\title{
URBAN LIVING
}

\section{Dear Reader,}

Are motorists turning into architects? If you have been following the activities of the OEMs in recent months and years, you might have had the impression that this was the case. Their business objective is no longer simply to sell cars, but to redesign cities, improve their infrastructure and make traffic flows more efficient.

The Urban research initiative launched by the German Federal Ministry for Economic Affairs and Energy and the industry, including Audi, BMW, Daimler, MAN, Opel and Volkswagen, together with Bosch and Continental, among others, shows how the cities and the city traffic of tomorrow can be better designed to meet our needs. The subproject concerning networked transport systems is intended to ensure that assistance systems can interact seamlessly with local traffic management centres to make highly automated driving possible.

\section{Audi has launched the Urban Future} Award with the aim of helping to resolve the problems of cities and mobility. Four international teams of experts, including urban planners and ethnographers, presented their concepts in May and will be vying with one another to win the prize in the autumn. The German team plans to restructure the airport at Berlin-Tegel to create a research and business park. Taking virtual valet parking as its key concept, the group from Boston aims to improve the use of space and increase the efficiency of the urban infrastructure by making intensive use of driver assistance systems.

The head of Mercedes-Benz Advanced Design Germany spirited away the 300 participants of the ATZlive bodywork event on 14 May into a visionary world of images showing the mobility systems of a large city in 2025. Holger Hutzenlaub considered the trends in urban architecture and infrastructure and concluded that the task of the designer, which had previously been restricted to determining the form of the vehicle, should be expanded to include the representation of the vehicle's context, in other words, the urban environment. The vehicle of the future will be both an office and a living room.

All of this sounds highly futuristic. Are we as individuals prepared to go along with it? Will we not simply become extras on a huge technological film set? It is not enough for technology and design to take on board urban planning and architecture as new areas of activity. People must also be ready for developments of this kind. It would make sense for designers to take greater account of the needs of a heterogeneous society, which includes young and old, rich and poor, and of the cultural differences between the Italians and the Japanese, for example, in their planning processes. The question they need to ask is whether this is what the customer really wants. First steps in the form of assistance systems and networking have already been taken, but the visionary world that has been outlined is still a long way off.

With best regards,

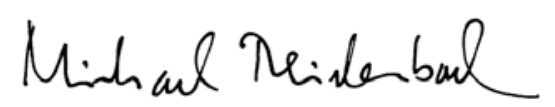

DIPL.-ING. MICHAEL REICHENBACH, Vice-Editor in Chief Wiesbaden, 6 June 2014

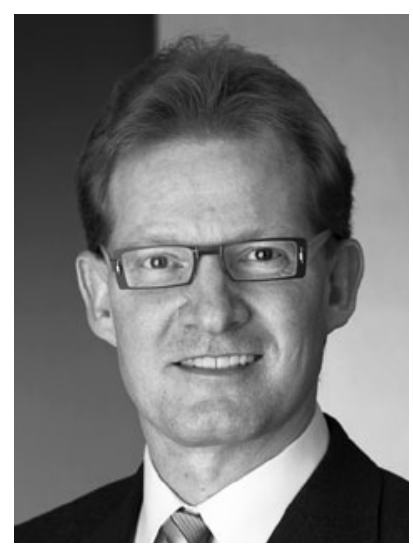

